\title{
Planning, Accounting and Control as Risk Management Tools for Small Business Investment Projects
}

\author{
Svitlana Bondarenko ${ }^{1 *}$, Natalya Shlafman ${ }^{2}$, Nataliia Kuprina ${ }^{3}$, Olga Kalaman ${ }^{3}$, \\ Olena Moravska ${ }^{4}$, Natalia Tsurkan ${ }^{5}$ \\ ${ }^{1}$ Kyiv National University of Culture and Arts, Yevhen Konovalets Street, 36, Kyiv, 01601, Ukraine \\ ${ }^{2}$ Institute of Market Problems and Economic-Ecological Research of the National Academy of Sciences of Ukraine, Frantsuz'kyy Blvd., \\ 29, Odessa, 65044, Ukraine \\ ${ }^{3}$ Odessa National Academy of Food Technologies, Kanatna Street, 112, Odessa, 65039, Ukraine \\ ${ }^{4}$ Precarpathian Institute name of M. Hrushevsky Interregional Academy of Personnel Management, Lviv region,, Street Ivasyuk, 21, \\ Truskavets, 82200, Ukraine \\ ${ }^{5}$ Interregional Academy of Personnel Management, Street Black Sea Cossacks, 19, Odessa,, 65003, Ukraine
}

\begin{abstract}
The purpose of this study is to develop scientifically sound proposals and recommendations for the implementation of planning, accounting and control tools in risk management of investment projects of small businesses. The relevance of this study is due to the need to provide small businesses with effective methods of risk management of the investment project, which can significantly reduce the negative impact of risk factors and achieve a significant effect from the investment. To achieve the goal of the study, methodological approaches were used to assess the risk sustainability of the enterprise, based on the assessment of the resource potential of the enterprise. A system of indicators is proposed to assess the quality of enterprise resources. Theoretical and methodological approaches to the formation of an early warning system in risk management have been developed. The proposed concept of indicative management includes tools for indicative control of investment projects in relation to the risk sustainability of the enterprise from the standpoint of its resource provision. Risks in this case become key indicators to which management actions should be directed. The introduction of a risk passport is proposed as a tool for early warning of crisis phenomena in small enterprises. The authors proved that the risk prevention system should be integrated into the overall organizational structure and become part of the enterprise management system. Indicative management is proposed as a tool for implementing functional strategies to prevent or eliminate threats and maximize their strengths and capabilities.
\end{abstract}

\section{Keywords:}

Planning;

Accounting;

Control;

Risk Management;

Investment Project;

Small Business.

\section{Article History:}

Received: 19 June 2021

Revised: 21 August 2021

Accepted: $\quad 02$ September 2021

Published: $01 \quad$ October 2021

\section{1- Introduction}

The investment activity of the enterprise is inextricably linked with the concept of risk, as there are no risk-free assets [1]. According to Rodchenko, et al., 2019; Petković, et al., 2016, for small businesses, the implementation of investment projects has characterized by the following features [2, 3]:

- The high risks of small businesses in combination with the high risks of investment activities create negative synergies, ie the risks of small innovative businesses become critical, threatening bankruptcy of small businesses;

\section{*CONTACT: lana.bond@ukr.net}

DOI: http://dx.doi.org/10.28991/esj-2021-01302

(C) 2021 by the authors. Licensee ESJ, Italy. This is an open access article under the terms and conditions of the Creative Commons Attribution (CC-BY) license (https://creativecommons.org/licenses/by/4.0/). 
- The high risks significantly complicate the search for and obtaining financing for small business investment projects;

- The insufficient state support for the needs of small business leads to postponement or refusal to implement promising investment projects by small businesses;

- The insufficient level of methodological and information support, the legal and the economic literacy in the field of small business lead to unreasonable decisions and inefficiency of investment project management.

As a rule, the investment projects have used to implement innovative product types. The investment activity has associated with the acquisition of competitive advantages in the market, with the possibility of selling innovative products (technologies) at high prices. Each of these factors carries additional risks of investment projects by a small enterprise. The investment risk is the probability of unforeseen financial losses in a situation of uncertainty of investment conditions. These include: the high duration of stages of development of production of innovative production; the high investment costs, with an increase in the final stages; the high level of risks throughout the innovation cycle, with loss of effect from investment. In some cases, the implementation of risk factors leads to the need to terminate projects and direct financial losses. In such conditions, the industrial enterprises need tools for correct assessment of investment risk. The use of such tools will allow managers to choose and implement effective methods of investment risk management, which can significantly reduce the negative impact of risk factors and achieve a significant effect from the investment. Lam (1997), Pringles, et al. (2015) highlight the following problematic aspects in the choice of risk management tools: $[4,5]$ :

- The conservatism of risk management models, which leads to low efficiency of risk assessment and limits the possibilities of control;

- The high level of uncertainty due to active transformations of the external and internal business environment of the enterprise;

- The low adaptive capacity of the regulatory framework and standards governing the system of internal control, audit and risk management;

- The insufficiency of scientific and the practical support of the risk management system: lack of theoretical basis for creative, non-trivial approaches to the assessment, planning, accounting and control of investment risks of small businesses;

- The insufficient involvement of specialists and scientists in the development of new solutions for dynamic risk management;

- The lack of scientific substantiation of the possibility of using modern digital tools for the risk modeling and risk flow management.

To overcome the outlined obstacles, it is necessary to systematically improve the management of processes of assessment, planning, accounting and control of investment risks of small businesses using more effective tools.

To date, risk management techniques have been developed for certain areas of the enterprise, such as analysis and assessment of financial risks, implementation of specific agreements, investment projects, risks in the development strategy, etc.

For small businesses, the main problematic aspects are the risks associated with the production and sale of products and the imperfection of the management system, i.e. the management crisis at all levels should be singled out. This necessitates the creation and development of early warning systems and associated adverse situations in enterprises. In this regard, the development of methodological support for risk identification and assessment and the development of an approach to the formation of an early warning system in the enterprise becomes relevant.

Of particular relevance is the issue of risk management in the management of innovative development of enterprises, the implementation of investment projects. It is proved that innovations have a positive impact on the sustainability of the enterprise, as they act as a tool to reduce the risk of non-compliance with market demands for new technological norms and standards. However, innovation is risky because it is associated with uncertainty about the perception of innovation in the market for new products and the likelihood of achieving goals. Innovative projects are characterized by increased risk, as their long-term actualizes the risks of negative macroeconomic and political factors.

Additional risks of innovation are associated with significant investments in the initial stages of the investment project. With incorrect forecasting and cash flow management from innovations, the company risks losing financial stability and solvency due to limited liquid assets.

Therefore, the concept of indicative management is proposed as a set of views on the problem of ensuring effective management of enterprises, which reflects the author's vision of promising areas of use in the management of an 
appropriately formed system of indicators. The purpose of the study is to develop scientifically sound proposals and recommendations for the implementation of planning, accounting and control tools in risk management of investment projects of small businesses.

In order to solve the problem of providing small businesses with the opportunity to carry out economic activities efficiently and stably, this study suggests the need to take into account in the management of the results of comparative analysis of deviations of selected indicators from regulatory (reference) values. That is, the hypothesis of the study is as follows: to clearly reflect changes in the main processes in the dynamics allow management indicators underlying indicative management, in which management decisions are made based on analysis of the situation by identifying the direction of the process.

The basic idea is that the created system of risk management of investment projects should become a full-fledged element of the management system of a small enterprise. The level of integration of the risk management system with the management system of the enterprise should ensure their complete merger. This will allow to manage risks systematically, comprehensively and ensure decision-making in all areas of activity: from strategy to operational management, will provide benefits in achieving targets, as well as in preventing the irrational use of necessary resources.

\section{2- Literature Review}

The risk investment project - probable event, or a number of them, which, if any, may affect the achievement of the goal at each stage of the investment project [6]. The project risks have the effect of accumulating probabilities of events affecting the project. In this case, the event itself can bring both benefits and harms, have different degrees of uncertainty, different causes and consequences (changes in labor costs, financial costs, failure of the action plan) (Figure 1).

Odds

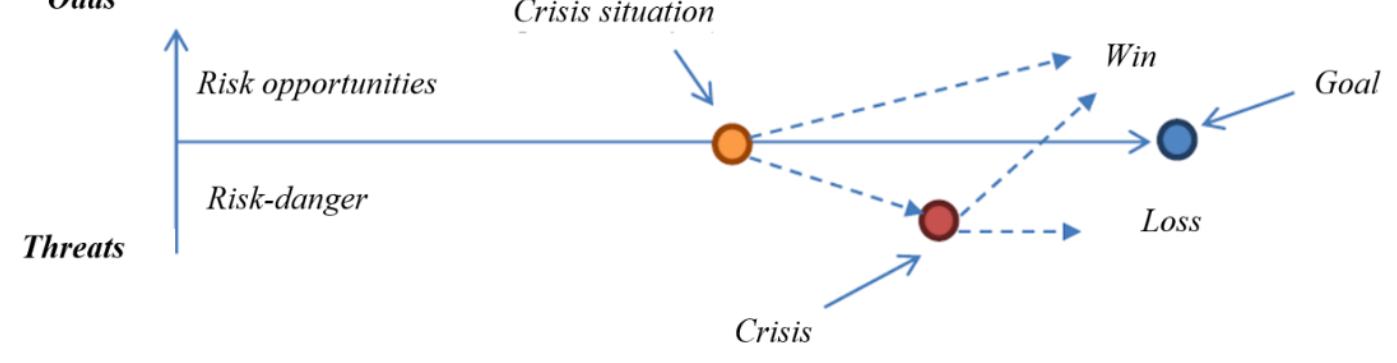

Figure 1. Risks and opportunities as criteria for the effectiveness of the investment project of the enterprise.

As can be seen from the diagram, the process of implementing the investment project of the enterprise has accompanied by risks-opportunities and risks-dangers. With inefficient management, ignoring potentially dangerous risks, a crisis situation arises at the local level. If the management does not take the necessary measures to overcome the situation, a crisis is inevitable. In both the first and the second variant, the way out of the crisis situation / crisis is possible when making management decisions that stabilize the situation. It should be emphasized that the way out of the crisis will be more "painful" and long in contrast to the way out of the crisis [7]. Therefore, it is very important to conduct a comprehensive diagnosis of situations at an earlier stage, applying in advance the risk management system of investment projects. The risk of the investment project has the following special features:

1. The probability or possibility of an adverse event at each stage of the life cycle of the investment project.

2. Uncertainty of the event and its consequences.

3. The fact of own investment of funds, which is the cause or non-occurrence of a risky event [8].

4. Consequences as loss of expected profit or other beneficial effects from the realized investments.

The essence of risk investment projects is to deviate from the planned course of events under the influence of various factors [9]. The term "risk" has defined as the possibility or danger of facing unfortunate consequences.

In practice, the following basic concepts of risk have used [10, 11]:

- The risk as a characteristic of potential danger, as an opportunity to implement negative events that cause harm;

- The risk as a measure of inconsistency between the results of decisions in terms of their usefulness, and as an opportunity to implement the worst alternatives;

- The risk as a relationship between losses and profitability, which includes the concept of "chance" - to obtain an unplanned benefit.

The analysis of different definitions of safety risk shows that the use of two groups of key terms is common: 
- "the probability", "the possibility", "the possible danger", "the threat", "a risk factor", "a danger factor", which characterize the randomness of the negative factor, probability, degree of possibility or frequency of occurrence of a negative event;

- "a loss", "a deviation of the result from the planned", relating to the consequences of this event.

So the risk investment project- is a category due to two components: the probability (possibility) of a dangerous event and the consequences of this event. The product of the probability of each $\mathrm{j}$-th event and the loss can be considered as the risk associated with this event:

$$
R_{j}=P_{j} \cdot S_{j}
$$

With reasonable estimates of the probability distribution of damage, it is possible to build a plausible model of risk assessment. The risk has considered as a measure or as an event of loss [12, 13, 14]. There are two possible risk measures: measure of the 1 st kind, which assesses the possibility of a risky event; measure of the 2 nd kind, denoting the immediate measured danger.

An event has considered risky if the necessary technical means can ensure the necessary security. Risk - an event in the form of a chain: where - the elements of the chain. The total risk of danger is the sum of the risks of the elements: $A_{i}=L\left(g_{i_{0}}, g_{i_{1}}, g_{i_{2}}, \ldots . . g_{i_{n}}\right) g_{i_{j}}$.

$$
\mu_{R} \sum \beta=\sum_{i(\beta)} m_{i}(P)
$$

where $\beta$ is the event number; $\mathrm{P}$ is the probability distribution on which the partial risks mi depend.

According to modern ideas, there can be no absolute security and there is always a residual risk. Therefore, the concept of "acceptable risk" has used. The NASA management defines acceptable risk as one that has understood and agreed by the project / program manager and the contracting authority as acceptable to achieve a certain criterion of success within the approved amount of resources [15].

The American Project Management Institute (PMI), which develops project management standards, describes procedures for proper risk management [15]. To date, risk management techniques have been developed, such as analysis and assessment of financial risks, implementation of specific agreements, investment projects, risks in the development strategy, etc. Figure 2 shows the classic risk management scheme.

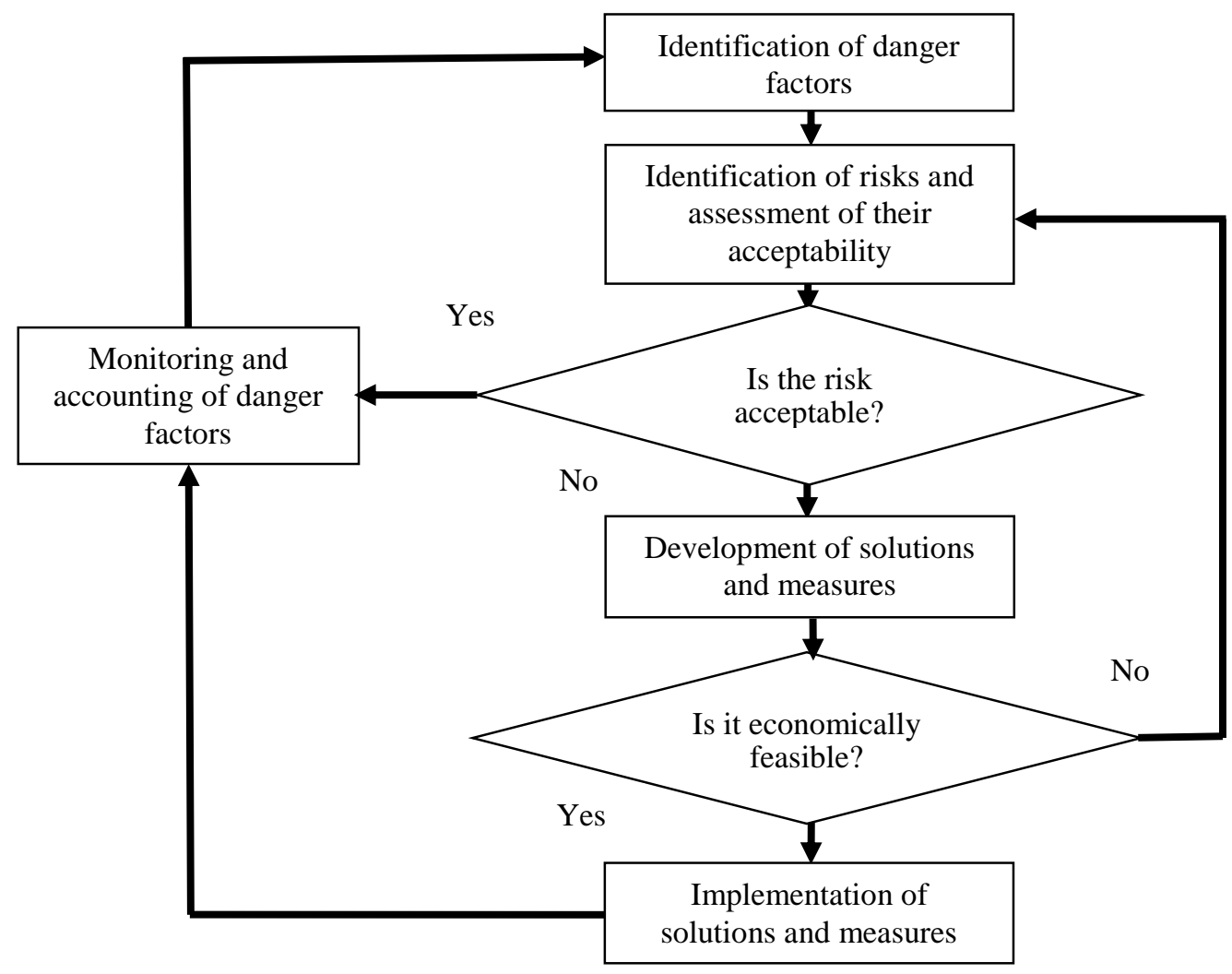

Figure 2. Risk management scheme. 
Thus, the risk management comes down to resource allocation decisions. Accordingly, the risk management methodology, as a set of management methods, is a decision support device for the rational use of resources to achieve the objectives of the investment project [16-18]. The risk management tasks of the investment project can be attributed to the tasks of situational management, which have characterized by the following properties:

1. The uniqueness of the object of management - it is necessary to take into account all the individual characteristics of each organization, the nature and scope of work performed, the level of "safety culture" and so on. The appropriate costs have required to fully describe the organization as an object of management.

2. The complexity of formalizing the purpose of the investment project. On the one hand, the goal is to make a profit from investment activities, and on the other hand, each organization declares in its policy to ensure the safety of its activities, employees, product, as the main purpose of the activity. This creates new difficulties in assessing the resources needed to ensure the safety goal of project management.

3. The classification of situations, combining them into classes, and the actual risk assessment of the investment project is largely subjective, so it is necessary to develop specific methods of risk management to reduce the degree of subjectivity.

4. Dynamics - the management system must be adaptive, ready to change its functioning. The risk management system of investment projects of the enterprise is constantly improved and developed.

5. Lack of optimality - it is impossible to assess the quality of the decision, if the alternatives were tested. If an event with a small loss occurs after a decision to minimize the risks of an investment project, it is not obvious that if another decision was made, this event would not have occurred or, conversely, a more severe event would have occurred $[19,20]$.

It has considered appropriate not to talk about the optimality, but only about the feasibility of the solution. Thus, risk management of an investment project is situational management, and will always be subjective, and therefore the task is to minimize the level of subjectivity.

\title{
3- Data and Methodology
}

The basis of this study was the methodology investment activity from the standpoint of project risk and risk sustainability of the enterprise, which has associated with the optimization of resource provision of the investment project in conditions of uncertainty and probability of achieving the goals. Within the limits of this research it is expedient to lean on the system approach on the basis of provisions of the theory of synergetics thanks to what the maximum coverage of all interrelations and consequences of the accepted decision becomes possible (Figure 3).

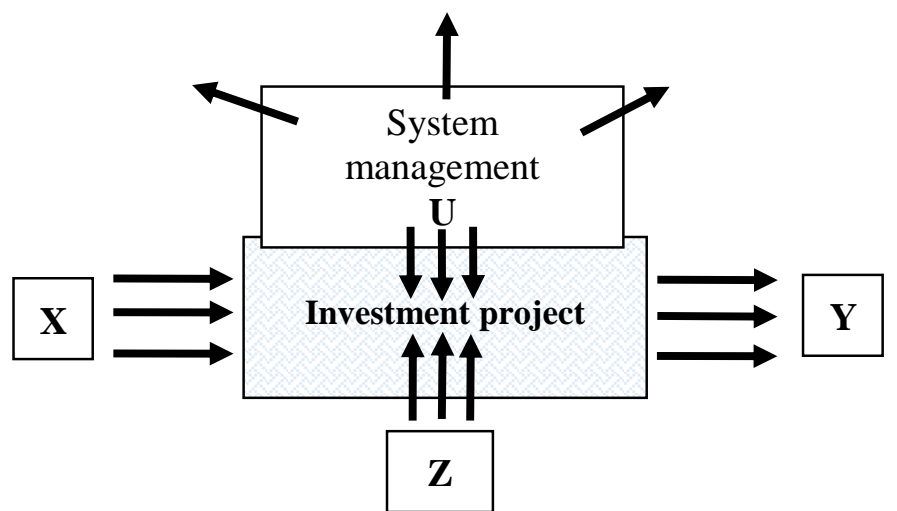

\begin{abstract}
where: $\mathrm{X}$ - input factor parameters of exogenous nature; $\mathrm{Y}$ - initial effective parameters of the organization of endogenous nature; $\mathrm{Z}$ - accidental influences and perturbations of the external organization of endogenous nature; $\mathrm{Z}$ - accidental influences and perturbations of the external
environment on the organization; $\mathrm{U}$ - parameters of organization management and regulation of the impact on the environment
\end{abstract}

Figure 3. The scheme of formation of uncertainty and risks in the interaction of the enterprise, as a complex socio-economic system, with the environment.

The investment projects have characterized by increased risk, as their long-term actualizes the risks of negative macroeconomic and political factors. Usually the life cycle of an investment project includes the following stages: the start of the project; the organization and the training; the execution of project works; the project completion.

Appropriate planning, accounting and control tools should be appropriate for the implementation of the investment project [21]. The additional investment risks are associated with significant investments in the initial stages of project implementation. With incorrect forecasting and cash flow management, the company risks losing financial stability and solvency due to limited liquid assets [22]. The risk management of investment projects has based on the systematic 
identification of factors / events that may affect the quality of prepared projects and their subsequent implementation, in order to achieve certain goals, increase the success of projects and reduce the impact of various risks to an acceptable level. The visually reflect the changes in these processes in the dynamics allow management indicators underlying indicative management, in which management decisions have made based on the analysis of the situation by identifying the direction of development of the studied process.

Methodological research tools include the process of identifying elements of a holistic risk management system, economic and financial analysis to assess the effects and risks of the investment project, systems analysis, the formation of tools for continuous improvement of the risk management process. The combination of these tools allowed us to develop an algorithmic model that reflects the logic of the functional components of the risk management system of investment projects of small businesses (Figure 4).

\section{The parts of the algorithmic model}

\section{Methodological tools}

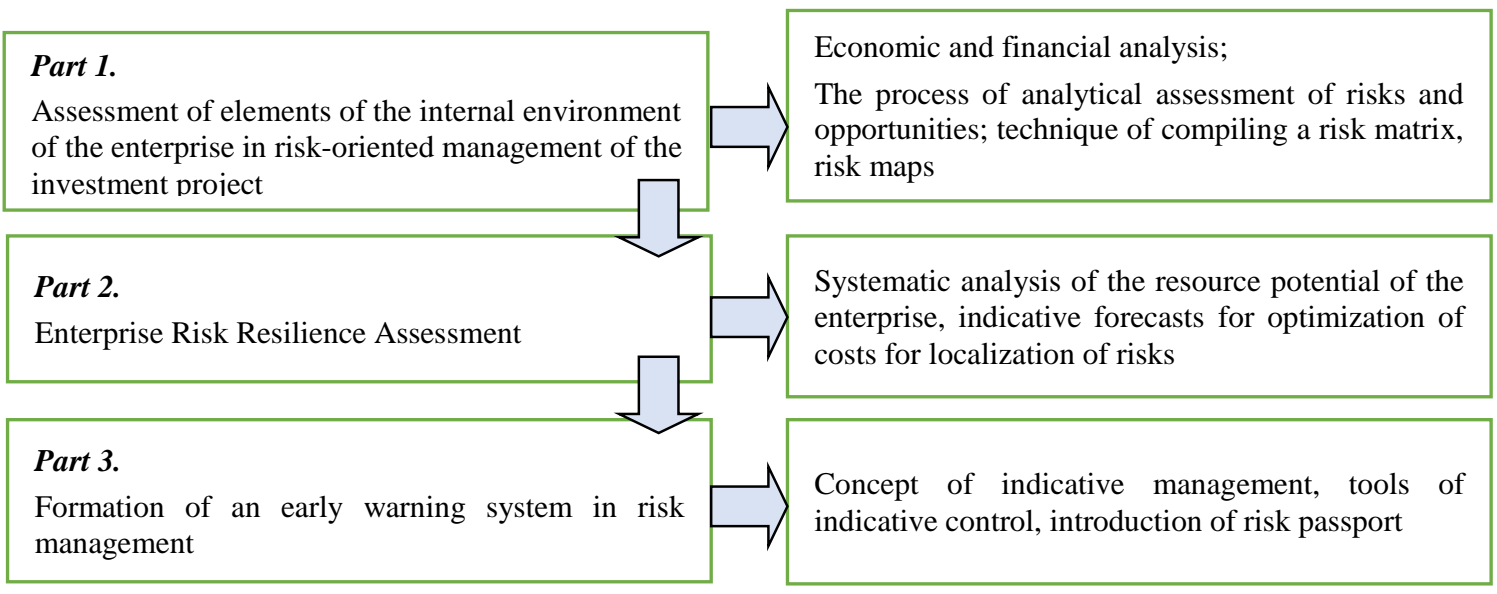

Figure 4. Algorithmic model for building a risk management system for investment projects of small businesses.

This study developed theoretical and methodological approaches to the formation of an early warning system in risk management, based on the concept of indicative management, which includes tools for indicative control of investment projects in relation to the risk of the enterprise from the standpoint of its resource provision. The concept of indicative management forms a toolkit of indicative control for the formation of an early warning system in risk management, reflects modern ideas about management decision-making methods based on the use of specially selected indicators and has implemented through a set of actions to improve the organization, according to indicative forecasts. in order to ensure the growth of economic efficiency.

For the small businesses, to ensure the stable success of investment projects, it is necessary to find the optimal balance between responding to risks and resilience to them. To diagnose the risk of the enterprise, it has proposed to use the method which has based on assessing the resource potential of the enterprise. It has proposed to allocate the following types of resources: production (fixed and working capital), financial, management and labor.

The resources of the enterprise must meet certain parameters: the quality of the resource, external threats to the resource, the internal vulnerability of the resource. A system of indicators has proposed to assess the quality of enterprise resources. The risks in this case become key indicators to which management actions should be directed. An effective tool for early warning of crises in the small businesses is the introduction of a risk passport.

As a result of the analysis of group of risks and their factors of objective character (external environment) and subjective (for internal environment of the enterprise) on the allocated business processes it will be possible to receive the information on kinds of risk, possibilities of their realization, the basic risk factors, spheres of their display. On the basis of the conducted analysis the portfolio of risks has formed. The risk prevention system becomes part of the enterprise management system and must be integrated into the overall structure. Based on the values of indicators and risks, the company must develop functional strategies to prevent or eliminate threats and maximize the use of its strengths and capabilities.

\section{4- Results}

\section{4-1- Risk Management Tools for Investment Projects in the Management System of the Enterprise}

The risk management - activities related to the identification (identification) and assessment of risks for the earliest detection of possible violations and shortcomings, inefficient use of resources [23]. The principles of development and implementation of risk management system are: systematic, continuity, balance of responsibility and initiative, a 
combination of analytics and risk heuristics, diversity, proactivity [24]. In the risk-oriented investment project management, the assessment of the strengths and weaknesses of the investment activities of the enterprise is a prerequisite for risk assessment. Assessment of elements of the internal environment of the enterprise in risk-oriented management includes the following elements: philosophy of risk management; risk perception culture; unity and ethical principles; striving for competence; management philosophy and work style; risk-appetite; the organizational structure; appointment of powers and responsibilities; personnel policy and practice $[25,26]$. The risk management is a repetitive process of systematic, proactive and cost-effective identification, assessment, mitigation and control of risks, taking into account such constraints as costs, the nature of the organization, quality, time frame and balanced use of appropriate resources [27, 28]. The risk management process involves the following procedures: the risk identification; the risk assessment; the identification of ways to respond to risks, a control measures. The scheme of an integrated risk management system has presented in Figure 5.

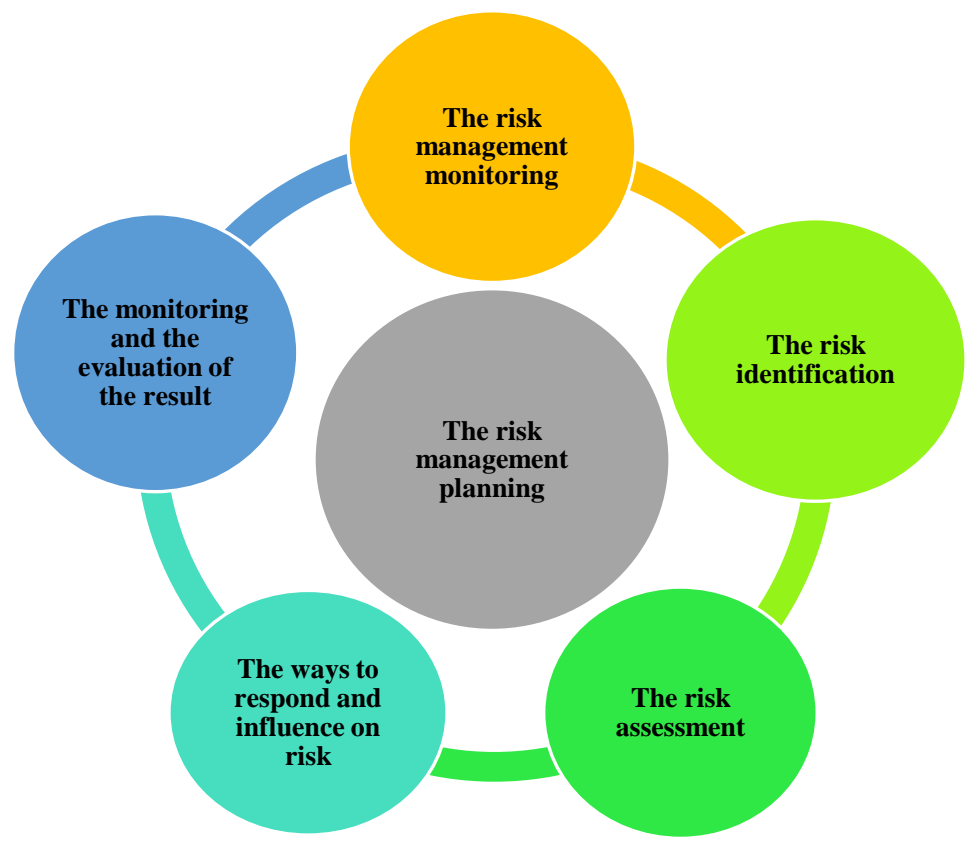

Figure 5. The scheme of an integrated risk management system of the investment project.

Risk management is an integral part of the management and implementation of tasks and functions performed by officials of the subject of internal control, which is to identify potential events that may affect the achievement of goals and objectives, risk assessment and identify ways to respond to risks and control measures to prevent or reduce their negative impact on the organization's achievement of goals and strategic goals [29]. During planning the strategy of the organization of process has defined, rules of interaction have defined. Planning has done by [30]:

- The formation of a management environment by popularizing the process for project participants and harmonizing their relationships;

- The involvement of ready-made templates, standards, schemes, common in this company management formats;

- The creating a description of the content of the project.

The main process tool is a meeting, which has attended by members of the project team, managers, persons responsible for the use of investments (if the risks of the investment project are planned). The result of planning is a document in which, in addition to the general provisions, must be entered:

- The methods and the tools of risk management by stages of implementation;

- The distribution of roles of project participants in case of risk situation and realization of threat;

- The permissible ranges and thresholds of risks;

- The principles of recalculation if the risks of investment projects change during the project;

- The rules and formats of reporting and record keeping;

- The monitoring formats.

In the general, the output should be clear to everyone algorithm of actions in the case of occurrence and implementation of threats. When forming an application for financing an investment project, the company's management can determine the type of investor that best suits its characteristics, needs and stages of development. For the 
implementation of investment projects, the small enterprises can attract the following sources of financial resources: a bank lending, a leasing, a venture financing, a public salesharesprivate company (Initial Public Offering, IPO). A comparison of these sources on a number of grounds relevant to a small enterprise, such as the term of financing, payment for funds, advantages and disadvantages for a financed enterprise, concluded that in conditions of ever-increasing uncertainty and a significant number of risks inherent in small industrial business, venture investment can be considered as a real financial basis for the implementation of the investment project. The venture capital market includes groups of investors who differ significantly from each other in the availability of financial resources and ways of interacting with the invested enterprise: a business angels, a venture companies, a large companies, a regional venture funds. Each of the groups of the venture investors, as a rule, specializes in a narrow segment of enterprises or projects, choosing them for a number of key factors. In turn, an important factor that investors take into account when making decisions about financing the company is the assessment of the expected profitability of the proposed investment project, the risks, as well as the period during which the costs will be reimbursed.

To assess these parameters, it is customary to use indicators of net discounted income (NPV), payback period, internal rate of return (IRR), etc. [31]. However, when evaluating investment projects, these indicators may not be reliable enough, due to the fact that for their calculation it is necessary to accurately forecast the cash flow generated by the project, the factors of which cannot be adequately estimated. The risk identification involves the identification and classification of risks into categories and types, as well as the systematic review of identified risks in order to identify new and / or those that have changed.

The purpose of the risk identification is to identify the risks of investment projects and opportunities at the earliest stage. In addition, at this stage it has recommended to take into account the interaction of risks, which can several times increase their potential impact or probability of occurrence, as well as to determine the root cause of these risks. The risk identification has usually carried out by an inter-functional group, whose members represent all involved units of the organization, which allows to ensure the completeness of the analysis.

Evaluation is an analysis of risks and opportunities that may lead to appropriate changes in the organization of the investment project, costing or timing of product implementation. Significance of risk can be assessed by measuring the level of its impact and probability of occurrence. It should be noted that the evaluation should be carried out on an objective basis and not in relation to the most or least favorable opportunities. The quantitative analysis shows the percentage probability of realization of risks and their consequences in numerical values. This analysis makes it possible to track how the profitability of the project will change when a quantitative change in a parameter from the list of critical risks for this project. When substituting algorithms into the current project model, thanks to quantitative analysis, it is easy to understand at what values the project will become unprofitable and which risk factors affect it more than others.

Sometimes a qualitative analysis, done with the involvement of experts and making an informed assessment, is enough to map the probability of risk and the degree of its impact on the project. At the output after the analytical part should be formed a ranked list: with prioritized risks; with positions that require clarification; with a risk assessment of the project as a whole.

The impact (numerical scale) on the goal (for example, cost, terms, content, quality, etc.) has considered. Each risk has assigned a rating, depending on its probability and the degree of impact on the target. This result can be clearly presented in the form of a risk matrix, which includes not only threats but also favorable opportunities created by the uncertainty of the situation (Table 1).

Table 1. The risk matrix of the investment project.

\begin{tabular}{|c|c|c|c|c|c|c|c|c|c|c|}
\hline Probability & \multicolumn{5}{|c|}{ Threats } & \multicolumn{5}{|c|}{ Opportunities } \\
\hline 0.9 & 0.05 & 0.09 & 0.28 & 0.48 & 0.68 & 0.68 & 0.48 & 0.28 & 0.09 & 0.05 \\
\hline 0.7 & 0.04 & 0.07 & 0.24 & 0.38 & 0.56 & 0.56 & 0.38 & 0.24 & 0.07 & 0.04 \\
\hline 0.5 & 0.03 & 0.05 & 0.20 & 0.20 & 0.40 & 0.40 & 0.20 & 0.20 & 0.05 & 0.03 \\
\hline 0.3 & 0.02 & 0.03 & 0.16 & 0.15 & 0.28 & 0.28 & 0.15 & 0.16 & 0.03 & 0.02 \\
\hline 0.1 & 0.01 & 0.10 & 0.13 & 0.07 & 0.15 & 0.15 & 0.07 & 0.13 & 0.10 & 0.01 \\
\hline Average rating & $\begin{array}{c}0.05 \\
\text { very low }\end{array}$ & $\begin{array}{l}0.10 \\
\text { low }\end{array}$ & $\begin{array}{c}0.30 \\
\text { average }\end{array}$ & $\begin{array}{l}0.50 \\
\text { high }\end{array}$ & $\begin{array}{c}0.70 \\
\text { very high }\end{array}$ & $\begin{array}{c}0.70 \\
\text { very high }\end{array}$ & $\begin{array}{l}0.50 \\
\text { high }\end{array}$ & $\begin{array}{c}0.30 \\
\text { average }\end{array}$ & $\begin{array}{l}0.10 \\
\text { low }\end{array}$ & $\begin{array}{c}0.05 \\
\text { very low }\end{array}$ \\
\hline
\end{tabular}

The matrix shows the thresholds set by the company for low, medium and high risks, which allows you to assess the risks in relation to a specific goal, as high, medium or low. The critical risks have marked in red, less significant - yellow, minor - green. For practical needs, objective quantification is paramount. Unfortunately, there is currently no single methodology for such an assessment. To some extent, the calculation of various indicators can be used. Some methods of quantitative risk assessment have presented in Table. 2. 
Table 2. Quantitative methods of risk assessment.

\begin{tabular}{|c|c|c|}
\hline Method name & The essence of the method & Output data \\
\hline $\begin{array}{l}\text { Human Reliability Assessment } \\
\text { (HRA) }\end{array}$ & $\begin{array}{l}\text { Human Reliability Assessment (HRA) on the system and } \\
\text { assessment of human errors affecting the system. }\end{array}$ & $\begin{array}{l}\text { Qualitative assessment of the actions of the human operator can be used } \\
\text { to identify its possible errors and their causes, which reduces the } \\
\text { likelihood of such errors. }\end{array}$ \\
\hline Analysis of the tree events & $\begin{array}{l}\text { To assess the probability of realization of events and their } \\
\text { transition to other events use inductive conclusions. }\end{array}$ & $\begin{array}{l}\text { - Description of possible problems in the form of combinations of } \\
\text { events; } \\
\text { - Quantitative estimates of frequency or probabilities of events; } \\
\text { - Reduction recommendations risk with an assessment of effectiveness. }\end{array}$ \\
\hline $\begin{array}{l}\text { Failure Mode and Effects } \\
\text { Analysis (FMEA) and Failure } \\
\text { Mode, Effects, and Criticality } \\
\text { Analysis (FMECA) }\end{array}$ & $\begin{array}{l}\text { Several types of FMEA: project (or product) of its } \\
\text { components, systems, maintenance process, software, etc. may } \\
\text { be accompanied by analysis criticality of the type of failure on } \\
\text { a qualitative, quantitative or mixed scale (FMECA). }\end{array}$ & $\begin{array}{l}\text { List of types of failures and their probability. Ranking significance of } \\
\text { failures, assessments failure probabilities, failure risk levels, or a } \\
\text { combination of risk levels and "opportunities detection "of the type of } \\
\text { refusal. }\end{array}$ \\
\hline $\begin{array}{l}\text { Technical service, directing to } \\
\text { software system reliability }\end{array}$ & $\begin{array}{l}\text { Method of identification and implementation of policy } \\
\text { maintenance aimed at achieving efficiency and effectiveness } \\
\text { necessary security, reliability and cost-effectiveness of } \\
\text { equipment, systems. }\end{array}$ & $\begin{array}{l}\text { Solving problems in the field of maintenance: technical monitoring } \\
\text { condition of equipment, systems, scheduled repairs, upgrades, fault } \\
\text { detection or current maintenance. }\end{array}$ \\
\hline $\begin{array}{l}\text { Layers of Protection Analysis } \\
\text { (LOPA) }\end{array}$ & $\begin{array}{l}\text { The LOPA method is based on the selection of pairs of causes } \\
\text { and consequences and the identification of protection levels } \\
\text { that can prevent a cause leading to an undesirable effect. }\end{array}$ & Recommendations for the use of controls and for risk reduction. \\
\hline The bow Tie analysis & $\begin{array}{l}\text { Schematic way to describe and analyze ways to implement risk } \\
\text { (from danger to consequences and results), as well as analysis } \\
\text { of management methods. Combined the logic of the fault tree } \\
\text { with (cause analysis) and event tree (consequences). }\end{array}$ & $\begin{array}{l}\text { Diagram of the main ways dangerous events and established prevention } \\
\text { barriers with performance evaluation. }\end{array}$ \\
\hline Markovsky analysis & $\begin{array}{l}\text { Analysis of complex renewable systems that may be in } \\
\text { different states, including those with degraded performance } \\
\text { efficiency. }\end{array}$ & $\begin{array}{l}\text { Probabilities of the system being in different states, estimating the } \\
\text { probabilities of failure and / or failure-free operation. }\end{array}$ \\
\hline Modeling Monte Carlo method & $\begin{array}{l}\text { Used to establish changes in the system that occur as a result } \\
\text { of changes in input data, taking into account the distribution of } \\
\text { input data and their relationship to the source data. The input } \\
\text { data can be described as random variables. }\end{array}$ & $\begin{array}{l}\text { Characteristics, distribution probability or frequency of failure; } \\
\text { probabilities of states; values of initial values. }\end{array}$ \\
\hline Real options method & $\begin{array}{l}\text { Management can be flexible in making decisions, in assessing } \\
\text { the effectiveness of the project by the method of real options. }\end{array}$ & $\begin{array}{l}\text { The assessment of the project by the method of real options takes into } \\
\text { account risk factors, which are presented in the form of a number of } \\
\text { complex options. }\end{array}$ \\
\hline
\end{tabular}

The quantitative methods have divided into deterministic, statistical, deterministic-statistical, probabilistic, statisticalprobabilistic, deterministic-probabilistic, logical-probabilistic, fuzzy sets, bifurcation, expert, etc. These methods allow to obtain numerical values of probabilities of events in the presence of initial data. The risk assessment process consists of several stages:

1. The identification of risks. This stage usually precedes the risk assessment itself. A list of potential risks that can only be encountered is developed, and then as part of the assessment itself, key risks are identified.

2. The development of risk assessment criteria (usually the probability of occurrence and materiality of the impact).

3. The assessment of each of the risks (according to the criteria), first a qualitative assessment of all risks, and then quantitative for key ones.

4. The assessment of the mutual influence of risks. Even seemingly insignificant interconnected risks can have a significant effect.

5. The prioritization of risks. The prioritization can be influenced by various factors, including reputational, security factors, rate of occurrence and prevention and, accordingly, the degree of vulnerability of the company.

6. The risk response is the final stage, which includes response options, response costs and follow-up, as well as the detailed development of a risk response plan.

Based on the assessment, a risk map has created, where all stages are clearly brought together, clear factors and a strategy for responding to those key risks or groups of risks. An example of a risk map has presented in Table 3. 
Table 3. Example of a risk map.

\begin{tabular}{|c|c|c|c|c|}
\hline The name of the risk & $\begin{array}{c}\text { Critical risk criterion, } \\
\text { thousand euro }\end{array}$ & Number of red risks & Number of yellow risks & Number of green risks \\
\hline- & 250 & - & - & - \\
\hline Currency and interest rate risk & 50 & 0 & 0 & 1 \\
\hline Liquidity risk & 18 & 0 & 0 & 1 \\
\hline Credit risk & 40 & 0 & 0 & 1 \\
\hline Tax risk & 12 & 0 & 0 & 1 \\
\hline Technical risk & 650 & 1 & 0 & 0 \\
\hline$\cdots \cdot$ & $\cdots$ & $\ldots$ & $\ldots$ & \\
\hline Aggregate risk & 1470 & 3 & 2 & 13 \\
\hline Maximum value & 580 & - & - & - \\
\hline
\end{tabular}

Once the risks and opportunities have been identified and assessed, appropriate action should be planned and taken. Such actions must include the planned date of implementation and conditions for the implementation of this event, as well as the appropriate division of responsibilities. The several actions can be developed for one risk. When choosing ways to respond, focus on the following main types of strategy:

- Evasion - elimination of sources of risk;

- Insurance (transfer) - involvement of a third party who assumes the risks;

- Minimization (reduction) - reducing the likelihood of a threat;

- Adoption - the passive form implies a conscious readiness to threaten, and the active form - the coordination of the action plan in the event of unforeseen but accepted circumstances.

Each method can be applied to its type of risk as optimal. Determining how to respond to identified and assessed risks is a decision to reduce, accept, distribute (transfer) or avoid the risk. The risk avoidance means the suspension (cessation) of activities that lead to increased risk. It involves modifying plans to achieve the required capabilities in such a way as to eliminate the threat posed by risk, to protect the ultimate objectives of the plan from the consequences of risk, or to review targets that are at risk.

The risk reduction means taking measures that reduce the likelihood of risk and / or its impact (consequences) to acceptable limits. Taking precautions to reduce the likelihood of risk or its consequences is often more effective. The distribution (transfer) of risk means the transfer or distribution of part of the risk. The risk transfer involves the transfer of the negative consequences of a threat with responsibility for responding to the risk to a third party. Thus, when transferring risk, the responsibility for managing it has transferred to the other side of the process, but the risk does not disappear. Acceptance of risk means that no action will be taken on it. Such a decision has made in cases where: the results of the risk assessment determine that its impact on the activity will be minimal and will not significantly affect the achievement of the goals and objectives of the plans to achieve the required capabilities; the cost of response measures outweighs the benefits of risk reduction or the likely adverse effects of the risk; possible methods of response create additional high risks; it is impossible to influence the risk.

The risk response decisions have made taking into account a certain acceptable level of risk ("risk-appetite") and risk tolerance (a certain number of risks that the organization is willing to accept in a particular category). Determining the acceptable level of risk and risk tolerance is a subjective process. When deciding on how to respond to risk, managers pay attention to: the assessment of the probability and impact of risk; the costs associated with responding to risk, compared with the benefits of its reduction; the whether the chosen way of responding to the risk does not create additional risks.

To achieve this operational goal, tasks and performance (indicative) indicators have been identified, as well as those responsible for implementation. On the basis of the conducted analysis the portfolio of risks is formed. An example of a risk passport has shown in Figure 6. The control and the management actions must be carried out throughout the project.

The onset of an unforeseen risk event in the final stages threatens greater losses than in the initial stages. Monitoring has carried out on a regular basis at intervals set by the organization, and ensures that all identified risks and opportunities are updated. Reporting on risks and opportunities should be part of the organization's documentation.

Monitoring reviews the values of already identified risks and sometimes identifies new ones. In addition, deviations and trends have analyzed, as well as the state of reserves needed to cover other risks. An effective tool for early warning of crises at enterprises is the introduction of a risk passport. 
RISK PASSPORT №

Name of risk

Unit

Risk owner

Responsible
PR-04 / FinDir

(identification number)

Risks of investment and innovation policy of the enterprise

(Investment and innovation business processes)

Finance department

(risk identification unit)

Financial Director Manevych M.A.

(position, surname, initials, signature)

Shirokov A.A.

(responsible provider of risk information, surname, initials, signature)

Source of risk

\begin{tabular}{c|l}
\hline Number & Name \\
\hline 1 & The probability of a negative change in the investment attractiveness of the enterprise as a result of the influence of external and internal factors. \\
\hline 2 & The probability of a negative change in the innovative activity of the enterprise as a result of the influence of external and internal factors. \\
\hline
\end{tabular}

\section{Source of risk № 1}

Name of the source of risk: The probability of a negative change in the investment attractiveness of the enterprise as a result of external and internal factors.

Risk source assessment

Evaluation date

22.08.20 p.

\begin{tabular}{|c|c|c|c|c|c|c|c|c|c|}
\hline \multicolumn{5}{|c|}{ Probability of occurrence $(\mathrm{Pq})$, points } & \multicolumn{5}{|c|}{ The magnitude of losses (Iq), points } \\
\hline 1 & 2 & 3 & 4 & 5 & 1 & 2 & 3 & 4 & 5 \\
\hline Weak-probable & Small-probable & Probable & Very likely & Almost possible & Minimal & Low & Medium & High & Maximum \\
\hline \multicolumn{10}{|c|}{$(\mathrm{R}=\mathrm{Pq} \cdot \mathrm{Iq})$} \\
\hline \multicolumn{5}{|c|}{ The degree of influence of the source of risk } & \multicolumn{5}{|c|}{ The level of risk source } \\
\hline $1 \leq \mathrm{R} \leq 4$ & $5 \leq R \leq 8$ & $9 \leq R \leq 10$ & $12 \leq \mathrm{R} \leq 16$ & $20 \leq R \leq 25$ & \multicolumn{2}{|c|}{$1 \leq R \leq 4$} & $5 \leq R \leq 10$ & \multicolumn{2}{|c|}{$12 \leq \mathrm{R} \leq 25$} \\
\hline Ignored & Minor & Moderate & Essential & Critical & \multicolumn{2}{|c|}{ Acceptable } & Justified & \multicolumn{2}{|c|}{ Inadmissible } \\
\hline
\end{tabular}

Processing the source of risk according to the results of the assessment

\begin{tabular}{|l|l|l|l|}
\hline Decrease & Adoption & Other \\
\hline
\end{tabular}

Risk management measures

\begin{tabular}{|c|c|c|c|}
\hline Name of events & Responsible & Strings & Resource \\
\hline 1. Monitoring of external factors, the change of which may affect the enterprise & $\begin{array}{l}\text { Manevich M.A. } \\
\text { Shirokov A.A. }\end{array}$ & Constantly & - \\
\hline 2. Monitoring of internal factors, the change of which may affect the enterprise & $\begin{array}{l}\text { Manevich M.A. } \\
\text { Shirokov A.A. }\end{array}$ & Constantly & - \\
\hline
\end{tabular}

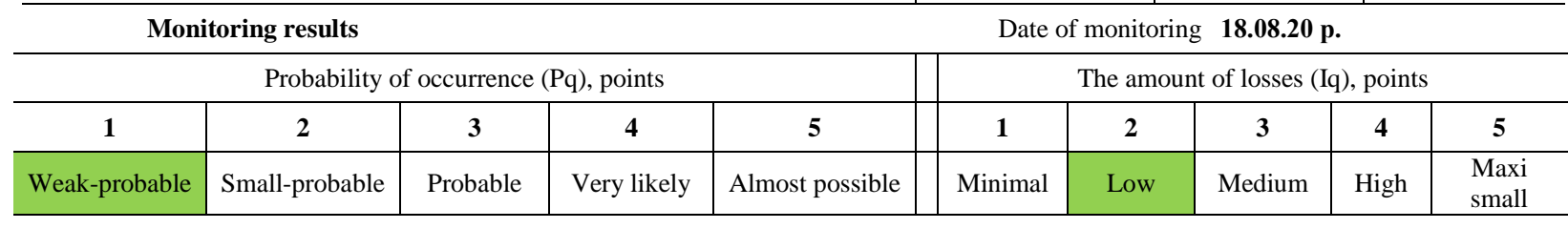

Risk index $\quad(\mathrm{R}=\mathrm{Pq} \cdot \mathrm{Iq}) \quad 2 \quad$ bali

\begin{tabular}{c|c|c|c|c|c|c|c}
\hline \multicolumn{4}{c|}{ The degree of influence of the source of risk } & \multicolumn{4}{c}{ The level of risk source } \\
\hline $1 \leq \mathrm{R} \leq 4$ & $5 \leq \mathrm{R} \leq 8$ & $9 \leq \mathrm{R} \leq 10$ & $12 \leq \mathrm{R} \leq 16$ & $20 \leq \mathrm{R} \leq 25$ & $1 \leq \mathrm{R} \leq 4$ & $5 \leq \mathrm{R} \leq 10$ & $12 \leq \mathrm{R} \leq 25$ \\
\hline Ignored & Minor & Moderate & Essential & Critical & Acceptable & Justified & Inadmissible \\
\hline
\end{tabular}

Processing of the risk source according to the monitoring results

\begin{tabular}{|l|l|l|l|}
\hline Decrease & Transfer \\
\hline
\end{tabular}

Figure 6. Example of a risk passport.

As a result of the analysis of group of risks and their factors of objective character (external environment) and subjective (for internal environment of the enterprise) on the allocated business processes it will be possible to receive the information on kinds of risk, possibilities of their realization, the basic risk factors, spheres of their 
display.Continuous improvement of the risk and opportunity management process includes regular analysis of the process for its integrity, stability, efficiency and effectiveness. It is necessary to make sure that the process has fully defined, the planned activities are implemented, and the set goals are achieved. The risk management system should include the ability to adapt to changing operational and tactical goals and objectives.

\section{4-2- Tools of Indicative Control for the Formation of an Early Warning System in Risk Management}

In order to solve the problem of providing a small business with the opportunity to carry out economic activities efficiently and stably, it is necessary creation of early warning systems of investment projects and related negative situations at enterprises. For small businesses to ensure stable success in the implementation of investment projects, it is necessary to find the optimal balance between responding to risks and resilience to them (Figure 7).

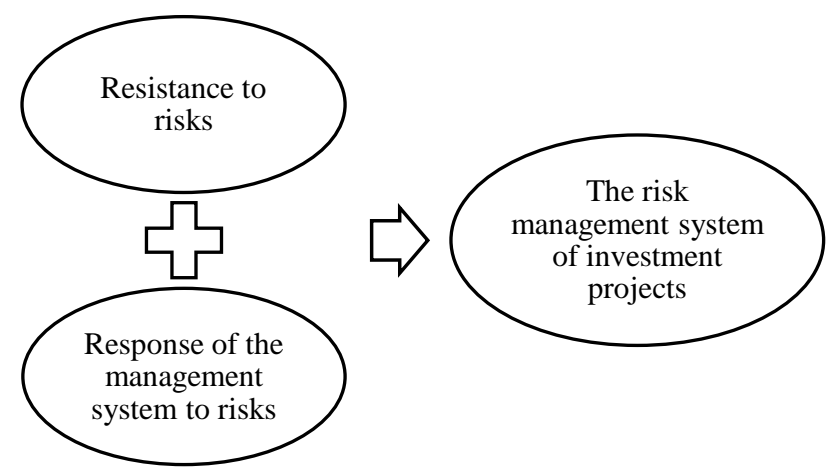

Figure 7. The scheme of components of risk resilience in the risk management system of investment projects.

The risk response is the ability to change and adapt the risk management infrastructure to respond quickly to changing market conditions, consumer preferences and market dynamics. The risk sustainability of enterprise projects is the ability to withstand the impact of destabilizing factors due to sustainable processes, control system, as well as means and methods of risk management of the investment project. According to the level of risk resistance and ability to respond to risks, enterprises can be divided into 4 categories (Figure 8).

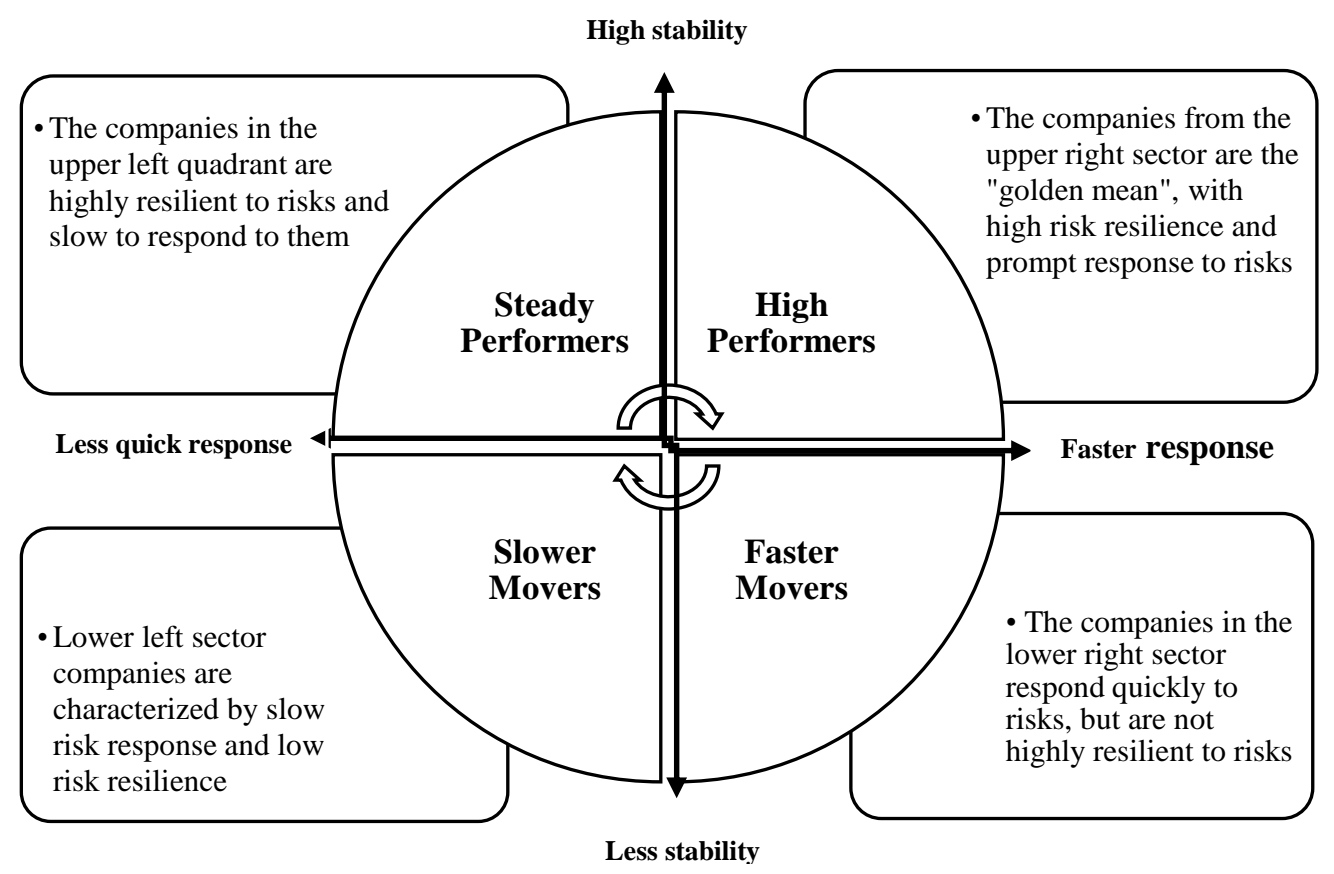

Figure 8. Construction of the matrix of risk resilience / risk response.

The enterprises that respond quickly to risks and show high risk resilience, form a strong risk management culture and appropriate structures that ensure the company's ability to withstand destabilizing risk events, which in turn leads to rapid and confident response to changes in risk profiles. The ability to respond to risks in itself stimulates the growth of the enterprise, when properly combined with risk resistance, it will increase competitiveness in the long run. 
The risk resistance involves the ability of the management system of the enterprise to localize the negative effects of risk factors, which has achieved by anticipatory management influence, due to the provided reserves. To diagnose the risk sustainability of a small business investment project, it has proposed to use the method which is based on assessing the resource potential of the enterprise. It has proposed to allocate the following types of resources: production (fixed and working capital), financial, management and labor. The resources of the enterprise must meet certain parameters: resource quality $\left(G_{i j}^{t}\right)$, external threats to the resource $\left(D_{i j}^{t}\right)$, internal vulnerability of the resource $\left(Z_{i j}^{t}\right)$. The quality of the resource means the ability of a particular resource of the enterprise or their combination to meet the conditions of the internal environment of the enterprise for its most effective use in the investment project. Calculations of the quality of resource potential have carried out according to the formula:

$G_{i j}^{t}=\frac{g_{i j}}{g_{\max }}$

where $\mathrm{t}$ is the study period; $i$ - the resource indicator; $\mathrm{g}_{\max }$ - normative value of the indicator.

To assess the external threats to enterprise resources and their internal vulnerability, it is advisable to use the method of expert assessments to select the most significant factors of external influence and internal vulnerability. And then the value of the parameter of the impact of external threats on the resources of the enterprise is calculated:

$D_{i j}^{t}=\frac{d_{i j}}{d_{\max }}$

where $d_{\max }$ is the normative value of the indicator.

The value of the parameter has calculated similarly internal vulnerability of the resource enterprises:

$Z_{i j}^{t}=\frac{z_{i j}}{z_{\max }}$

where $\mathrm{z}_{\max }$ - normative value of the indicator.

The integrated risk index has calculated by the formula:

$R_{s t}^{f a t}=\sum_{i=1}^{4} G_{i j}^{t} \times D_{i j}^{t} \times Z_{i j}^{t} \times w$

where $R_{s t}^{\text {fact }}$ - the actual value of the risk of the enterprise for the study period; $w$ - the importance of this resource in the overall resource potential.

Let's rank the indicators of internal resource potential of the enterprise according to the degree of value of the resource. Ranking has carried out by the method of expert survey, the experts were leading specialists of accounting, technical and engineering departments. The most important for investment projects of small enterprises are production resources, as they are a prerequisite for identifying the possibility of efficient use of labor, management and financial resources, as well as determining the impact of technical and organizational development measures on final results, including volume and quality, cost and profitability. Products, as well as the level of profitability of economic activity. To assess the quality of enterprise resources, the following system of indicators has proposed (Table 4).

Table 4. System of indicators for assessing the quality of enterprise resources for diagnosing the risk sustainability of the investment project.

\begin{tabular}{|c|c|c|}
\hline \multicolumn{3}{|c|}{ Calculation of the quality factor of production resources } \\
\hline $\begin{array}{l}\text { Indicators of property valuation and use of } \\
\text { fixed assets }\end{array}$ & $\begin{array}{l}\text { Indicators of the state and efficiency of } \\
\text { current assets }\end{array}$ & Indicators of the use of intangible assets \\
\hline $\begin{array}{l}\text { The coefficient of suitability of fixed assets } \\
\text { (inverse to the coefficient of depreciation) }\end{array}$ & \multirow{3}{*}{ Inventory turnover ratio } & \multirow{3}{*}{$\begin{array}{l}\text { Coefficient of production return of intangible } \\
\text { assets }\end{array}$} \\
\hline Update rate & & \\
\hline Return on investment & & \\
\hline Capital adequacy ratio & \multirow{4}{*}{ Material return of products } & \multirow{3}{*}{ Suitability ratio of intangible assets } \\
\hline Load factor & & \\
\hline Intensity of use & & \\
\hline Integral load factor & & Number of purchased / received licenses, patents \\
\hline \multicolumn{3}{|c|}{$G_{\text {production resources }}^{t}=\sqrt[3]{G_{\text {property status }}^{t} \times G_{\text {turnover }}^{t} \times G_{\text {intangible assets }}^{t}}$} \\
\hline \multicolumn{3}{|c|}{ Calculation of the quality factor of financial resources } \\
\hline Liquidity ratios & Indicators of financial stability & Indicators of profitability and business activity \\
\hline
\end{tabular}




\begin{tabular}{|c|c|c|c|}
\hline Absolute liquidity ratio & \multicolumn{2}{|c|}{ Coefficient of autonomy } & Profitability (loss) of assets \\
\hline Rapid liquidity ratio & \multicolumn{2}{|c|}{ Coefficient of financial stability } & Return on (unprofitable) equity \\
\hline \multirow{2}{*}{ Coverage ratio } & \multicolumn{2}{|c|}{ Equity maneuverability ratio } & Profitability (loss) of activity \\
\hline & \multicolumn{2}{|l|}{ Equity ratio } & Profitability (loss) of products \\
\hline \multicolumn{4}{|l|}{$G_{\text {financial resources }}^{t}=\sqrt[3]{ }$} \\
\hline \multicolumn{4}{|c|}{ Calculation of the quality factor of management resources (Qualitative indicators) } \\
\hline \multicolumn{4}{|l|}{ Speed of management decisions } \\
\hline \multicolumn{4}{|l|}{ Availability of effective feedback } \\
\hline \multicolumn{4}{|l|}{ Quality of activity planning } \\
\hline \multicolumn{4}{|c|}{ The effectiveness of the organizational structure, its compliance with the needs of the enterprise } \\
\hline \multicolumn{4}{|c|}{ Calculation of the quality factor of labor resources } \\
\hline \multicolumn{2}{|l|}{ Relative quantitative indicators } & \multicolumn{2}{|c|}{ Qualitative indicators } \\
\hline \multicolumn{2}{|l|}{ Productivity } & \multirow{2}{*}{\multicolumn{2}{|c|}{ Compliance of the professional staff of the profile of the enterprise }} \\
\hline \multicolumn{2}{|l|}{ Staff turnover ratio } & & \\
\hline \multicolumn{2}{|c|}{ Balance of working time (ratio of productive and unproductive time) } & \multicolumn{2}{|c|}{ Sufficiency of experience of technological personnel } \\
\hline & abor resources $={ }^{2}$ & $G_{\text {quantita }}^{t}$ & lity \\
\hline
\end{tabular}

The second place has occupied by financial resources, which, in turn, are used by enterprises to form their assets and carry out production and financial activities to obtain the appropriate income, profit. The third link in the resource potential has occupied by management resources, which show the ability of the management system of the enterprise to ensure its sustainable market position and economic development. For evaluation weight maturity in the total resource potential, a weight matrix has proposed (Table 5).

Table 5. Matrix of weight of resources as a part of resource potential enterprises.

\begin{tabular}{c|c|c|c}
\hline Resource type & Rank & Inverse rank A $=\frac{1}{\text { rank }}$ & Validity $w=\frac{\mathrm{A}}{\sum \mathrm{A}}$ \\
\hline Production resources & 1 & 1.00 & 0.48 \\
\hline Financial resources & 2 & 0.50 & 0.24 \\
\hline Management resources & 3 & 0.33 & 0.16 \\
\hline Workforce & 4 & 2.08 & 1 \\
\hline Total & & & 1 \\
\hline
\end{tabular}

The obtained values of integrated indicators of the level of risk stability of the enterprise are within the range [0; 1] or from 0 to $100 \%$, respectively. The greater the value of the indicator, the higher the risk stability of the enterprise. For the normal functioning of the enterprise, the risk factor must be equal to 1 , if this value is greater than 1 , it means that the company has a risk margin. Given the results of the preliminary analysis, there is a functional dependence of the level of economic stability of the enterprise $\left((\bar{F})\right.$, from the level of its risk resistance $\left(R_{s t}^{\text {fact }}\right)$, which, in turn, depends on the cost of its provision and maintenance $(\mathrm{V})$ :

$$
\begin{aligned}
& F=f F\left(R_{s t}^{f a c t}\right) \\
& V=f V\left(R_{s t}^{\text {fact }}\right)
\end{aligned}
$$

The optimal value of the risk level indicator:

$$
\left\{\begin{array}{l}
\frac{F}{V} \rightarrow \max \\
V \leq V_{\max } \\
F \geq F_{\min } \\
0 \leq R_{s t}^{\text {fact }} \leq R_{s t}^{\max }
\end{array}\right.
$$

where Vmax - the maximum allowable amount of costs to ensure the risk stability of the enterprise, thousand UAH; Fmin- the minimum allowable level of economic stability of the enterprise, measured on a scale [0-1] (relative assessment); $R_{s t}^{\max }$ - the maximum assessment of the level of risk stability of the enterprise on the accepted scale. The management measures to reconcile levels of efficiency and risk is one of the key tasks of the management system. After 
all, uncertainty and high innovation risks lead to potential losses of efficiency, so the task of management is to localize and / or neutralize possible risks, for which it is necessary to provide an increase in investment costs, comparing them with the amount of losses. The main principle of optimizing the cost of risk localization is the principle of not exceeding the amount of costs compared to the amount of possible losses. Rational distribution of limited resources between the main and auxiliary processes and innovative projects allows the company to implement these projects as a result of achieving sustainability. To increase the chances of a successful outcome, it is necessary to introduce some control over events and the relationship between events.

\section{5- Conclusion}

This study examines the main aspects introduction of planning, accounting and control tools in risk management of investment projects of the small businesses. The necessity of integration of the risk management system with the enterprise management system is proved. Theoretical and methodological approaches to the formation of an early warning system in risk management, based on the concept of indicative management, which includes tools for indicative control of investment projects in relation to the risk of the enterprise from the standpoint of its resource provision. To diagnose the risk of the enterprise, it has proposed to use the method which has based on assessing the resource potential of the enterprise. It has proposed to allocate the following types of resources: production (fixed and working capital), financial, management and labor.The resources of the enterprise must meet certain parameters: the quality of the resource, external threats to the resource, the internal vulnerability of the resource. A system of indicators has proposed to assess the quality of enterprise resources. The risks in this case become key indicators to which management actions should be directed. The introduction of a risk passport has proposed as a tool for early warning of crisis phenomena in small enterprises. On the basis of the conducted analysis the portfolio of risks has formed.The risk prevention system becomes part of the enterprise management system and must be integrated into the overall structure. Based on the values of indicators and risks, the company must develop functional strategies to prevent or eliminate threats and maximize the use of its strengths and capabilities.

\section{6- Declarations}

\section{6-1-Author Contributions}

S.B., N.S., N.K., O.K., O.M., N.T. contributed to the design and implementation of the research, to the analysis of the results and to the writing of the manuscript. All authors have read and agreed to the published version of the manuscript.

\section{6-2-Data Availability Statement}

The data presented in this study are available on request from the corresponding author.

\section{6-3- Funding}

The authors received no financial support for the research, authorship, and/or publication of this article.

\section{6-4- Conflicts of Interest}

The authors declare that there is no conflict of interests regarding the publication of this manuscript. In addition, the ethical issues, including plagiarism, informed consent, misconduct, data fabrication and/or falsification, double publication and/or submission, and redundancies have been completely observed by the authors.

\section{7- References}

[1] Reeb, David M., Chuck C. Y. Kwok, and H. Young Baek. "Systematic Risk of the Multinational Corporation." Journal of International Business Studies 29, no. 2 (June 1998): 263-279. doi:10.1057/palgrave.jibs.8490036.

[2] Petković, Dalibor, Shahaboddin Shamshirband, Amirrudin Kamsin, Malrey Lee, Obrad Anicic, and Vlastimir Nikolić. "RETRACTED: Survey of the Most Influential Parameters on the Wind Farm Net Present Value (NPV) by Adaptive NeuroFuzzy Approach.” Renewable and Sustainable Energy Reviews 57 (May 2016): 1270-1278. doi:10.1016/j.rser.2015.12.175.

[3] Rodchenko, L., Goncharenko, O., Koval, O., Tarasov, I., Nemchenko, H. \& Tkachuk T. "Optimization of Innovation Projects According To Criteria of Time and Resource Constraints." Regular Issue 8, no. 3 (September 30, 2019): 1431-1434. doi:10.35940/ijrte.b3706.098319.

[4] Lam, Juan Carlos, Magnus Heitzler, Jürgen Hackl, Bryan T. Adey, and Lorenz Hurni. "Modelling the Functional Capacity Losses of Networks Exposed to Hazards." Sustainable and Resilient Infrastructure 5, no. 1-2 (May 31, 2018): 30-48. doi:10.1080/23789689.2018.1469357.

[5] Pringles, Rolando, Fernando Olsina, and Francisco Garcés. "Real Option Valuation of Power Transmission Investments by Stochastic Simulation.” Energy Economics 47 (January 2015): 215-226. doi:10.1016/j.eneco.2014.11.011. 
[6] Korepanov, Georgii and Yatskevych, Inna and Popova, Olha and Shevtsiv, Liubov and Marych, Maksym and Purtskhvanidze, Olga, "Managing the Financial Stability Potential of Crisis Enterprises." International Journal of Advanced Research in Engineering and Technology (IJARET) 11, no.4 (May 13, 2020): 359-371.

[7] Khomutenko, A., Mishchenko, A., Ripenko, A., Liulchak, Z. \& Hrozovskyi, R. "Tools of the Neuro-Fuzzy Model of Information Risk Management in National Security.” International Journal of Engineering and Advanced Technology 8, no. 6 (August 30, 2019): 4526-4530. doi:10.35940/ijeat.f8842.088619.

[8] Ioulianou, Sophocles, Michael J. Leiblein, and Lenos Trigeorgis. "The Impact of Real Options Awareness on Downside Risk in Multinational Firms." Academy of Management Proceedings 2018, no. 1 (August 2018): 12170. doi:10.5465/ambpp.2018.12170abstract.

[9] Popov, Oleksandr, Anna Iatsyshyn, Dmytro Sokolov, Maksym Dement, Ihor Neklonskyi, and Alexander Yelizarov. “Application of Virtual and Augmented Reality at Nuclear Power Plants.” Systems, Decision and Control in Energy II (2021): 243-260. doi:10.1007/978-3-030-69189-9_14.

[10] Görög, Mihály. “A Broader Approach to Organisational Project Management Maturity Assessment.” International Journal of Project Management 34, no. 8 (November 2016): 1658-1669. doi:10.1016/j.ijproman.2016.08.011.

[11] Hubanova, Tamara, Rostyslav Shchokin, Oleh Hubanov, Volodymyr Antonov, Pavlo Slobodianiuk, and Sergiy Podolyaka. "Information Technologies in Improving Crime Prevention Mechanisms in the Border Regions of Southern Ukraine." Journal of Information Technology Management (2021): 75-90. doi:10.22059/JITM.2021.80738.

[12] Dykha, Mariia, Yuliia Cheban, Olena I. Bilyk, Zinoviy O. Siryk, Olena Khytra, and Alla Dudnyk. "Management of corporate social activity in the organization." International Journal of Management 11, no. 5 (2020): 97-107.

[13] Eisele, Wolfgang, and Alois Paul Knobloch. "Value at Risk: Tool for Managing Trading Risks.” Risk Management (2000): 155179. doi:10.1007/978-3-662-04008-9_9.

[14] Engel, J. \& Gizicki, M. "Conservatism, accuracy and efficiency: Comparing Value at Risk methods.” Discussion paper 2. Australian Prudential Regulation Authority, Reserve Bank of Australia, (March, 1999): 49-51.

[15] Rose, Kenneth H. “A Guide to the Project Management Body of Knowledge (PMBOK® Guide)-Fifth Edition.” Project Management Journal 44, no. 3 (May 30, 2013):586. doi:10.1002/pmj.21345.

[16] Del Caño, Alfredo, and M. Pilar de la Cruz. "Integrated Methodology for Project Risk Management." Journal of Construction Engineering and Management 128, no. 6 (December 2002): 473-485. doi:10.1061/(asce)0733-9364(2002)128:6(473).

[17] Backlund, F., D. Chronéer, and E. Sundqvist. "Project Management Maturity Models - A Critical Review." Procedia - Social and Behavioral Sciences 119 (March 2014): 837-846. doi:10.1016/j.sbspro.2014.03.094.

[18] Bondarenko, Svitlana, Oleksandr Halachenko, Leonid Shmorgun, Iryna Volokhova, Alla Khomutenko, and Valerii Krainov. "The Effectiveness of Network Systems in Providing Project Maturity of Public Management." TEM Journal (February 27, 2021): 272-282. doi:10.18421/tem101-34.

[19] Behn, R.D. Rethinking Democratic Accountability, Washington: Brookings. 26. (2001): 328.

[20] Belderbos, René, Tony W. Tong, and Shubin Wu. "Multinationality and Downside Risk: The Roles of Option Portfolio and Organization.” Strategic Management Journal 35, no. 1 (April 8, 2013): 88-106. doi:10.1002/smj.2087.

[21] Trivić, Jelena, and Saša Petković. "Different Features of Transition Economies: Institutions Matter." Family Businesses in Transition Economies (2015): 71-96. doi:10.1007/978-3-319-14209-8_4.

[22] Wiklund, Johan, and Dean Shepherd. "Entrepreneurial Orientation and Small Business Performance: a Configurational Approach.” Journal of Business Venturing 20, no. 1 (January 2005): 71-91. doi:10.1016/j.jbusvent.2004.01.001.

[23] Bondarenko, S., Ivanchenkova, L., Okhrimenko, O., Zybareva, O., Karpitskaya, M. \& Huz, M. Risk Management of Enterprise Restructuring Strategy. International Journal of Advanced Research in Engineering and Technology, 11(5), (2020): 14-25.

[24] Cherchyk, Larysa, Liubov Korchynska, and Vitalina Babenko. "Using Model Forests as a Form of Balanced Forestry in Ukraine.” Forestry Studies 71, no. 1 (December 1, 2019): 69-85. doi:10.2478/fsmu-2019-0013.

[25] Bondarenko, Svitlana, Volodymyr Lagodienko, Iryna Sedikova, and Olga Kalaman. "Application of project analysis software in project management in the pre-investment phase." Journal of Mechanical Engineering and Technology 9, no. 13 (2018): 676684.

[26] Demir, C., and İbrahim Kocabaş. "Project Management Maturity Model (PMMM) in Educational Organizations.” Procedia Social and Behavioral Sciences 9 (2010): 1641-1645. doi:10.1016/j.sbspro.2010.12.379.

[27] Klochan, Viacheslav, Igor Piliaiev, Tetyana Sydorenko, Vira Khomutenko, Anton Solomko, and Alona Tkachuk. "Digital Platforms as a tool for the transformation of strategic Consulting in Public Administration." Journal of Information Technology Management (2021): 42-61. doi:10.22059/JITM.2021.80736. 
[28] Zhang, Mingwu, Shaochen Zhang, and Lein Harn. "An Efficient and Adaptive Data-Hiding Scheme Based on Secure Random Matrix.” Edited by Hua Wang. PLOS ONE 14, no. 10 (October 2, 2019): e0222892. doi:10.1371/journal.pone.0222892.

[29] Rezaei, Jafar, Roland Ortt, and Victor Scholten. “An Improved Fuzzy Preference Programming to Evaluate Entrepreneurship Orientation.” Applied Soft Computing 13, no. 5 (May 2013): 2749-2758. doi:10.1016/j.asoc.2012.11.012.

[30] Slater, Stanley F., and John C. Narver. "The Positive Effect of a Market Orientation on Business Profitability." Journal of Business Research 48, no. 1 (April 2000): 69-73. doi:10.1016/s0148-2963(98)00077-0.

[31] Mizutani, Fuminobu. "SROI with Assurance Can Help Contributors Distinguish Hypocritical Organizations from Genuine NFPs.” Emerging Science Journal 5, no. 1 (February 1, 2021): 16-24. doi:10.28991/esj-2021-01253. 